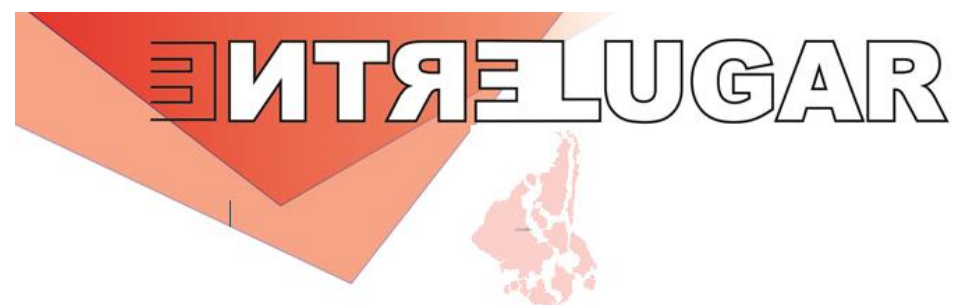

\title{
PROPRIEDADES TÉRMICAS DO SOLO NA SUB-BACIA HIDROGRÁFICA DO RIO GURGUÉIA-PIAUÍ-BRASIL
}

\author{
SOIL'S THERMAL PROPERTIES IN THE HYDROGRAPHIC SUB-BASIN OF \\ THE GURGUÉIA RIVER-PIAUÍ-BRAZIL
}

\author{
PROPIEDADES TÉRMICAS DEL SUELO EN LA CUENCA DEL RÍO \\ GURGUÉIA-PIAUÍ-BRASIL
}

\author{
Livania Norberta de Oliveira \\ livaniageo@gmail.com \\ Universidade Federal do Piauí \\ Cláudia Maria Sabóia de Aquino \\ cmsaboia@gmail.com \\ Universidade Federal do Piauí
}

Resumo: O conhecimento das propriedades térmicas do solo é fundamental para o entendimento dos processos físicos existentes no ambiente. Desta forma, objetiva-se neste estudo, analisar a variação da temperatura do solo na sub-bacia hidrográfica do rio Gurguéia-Piauí, entre os anos de 1987 e 2017 com o propósito de subsidiar ações sustentáveis para a região que pertence a atual fronteira do agronegócio brasileiro. Utilizou-se de pesquisa bibliográfica e documental, assim como do SIG ArcGis para o mapeamento da área. Constatou-se que a bacia apresentou variação térmica do solo entre os anos analisados, em decorrência do aumento do solo exposto devido o avanço da fronteira agrícola no Estado, que em 2017 apresentou em aproximadamente 42\% da área temperatura do solo acima de $30^{\circ} \mathrm{C}$, podendo comprometer a manutenção das atividades agrícolas atuais no decorrer do tempo. Desta forma, torna-se essencial para a sustentabilidade do ambiente que seja feito o planejamento e gerenciamento da sub-bacia do rio Gurguéia, utilizando como parâmetro a temperatura do solo, buscando incorporar todos os recursos ambientais da área de drenagem, assim como integrar os aspectos ambientais, sociais, econômicos e políticos da área.

Palavras-chave: Bacia hidrográfica, Solo, Temperatura, Fronteira agrícola, Rio Gurguéia

Abstract: The knowledge of the soil's thermal properties is essential for the understanding of physical processes that exists in the environment. Therefore, this study aims to analyze variation of soil temperature in the hydrographic sub-basin of the Gurguéia-Piauí River, between 1987 and 2017 for the purpose of subsidize sustainable actions for the region that belongs to the current frontier of brazilian agribusiness. It was 


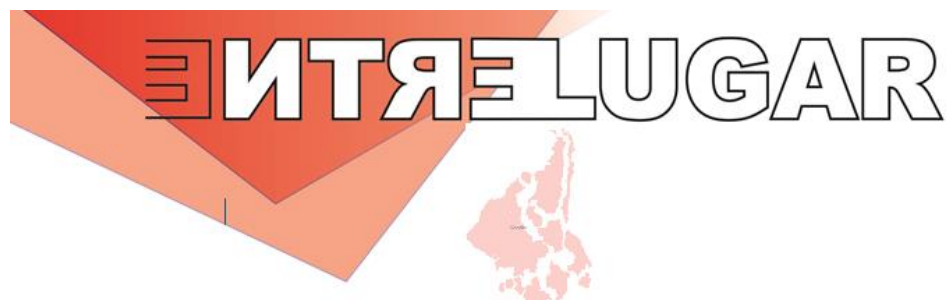

used bibliographic and document research, as well as of the ArcGis GIS to mapping the area. It was observed that the basin presented variation of soil temperature between the years analized, as a result of increasing of the exposed soil due to the progress of agricultural border in the state, in 2017 it was presented approximately $42 \%$ of the area, the soil temperature over $30^{\circ} \mathrm{C}$, committing the maintenance of current agricultural activities over time. So, it is essential to sustainability of the environment that planning an management of the sub-basin of the Gurguéia river have to be done, using as a baseline the soil temperature, by incorporating all the environmental resources of the drainage area, just as integrate environmental, social, economical and political aspects of the region.

Keywords: Hydrographic basin, Soil. Temperature, Agricultural frontier, Gurguéia River.

Resumen: El conocimiento de las propiedades térmicas del suelo es fundamental para la comprensión de los procesos físicos existentes en el medio ambiente. Por lo tanto, el objetivo de este estudio es analizar la variación de la temperatura del suelo en la subcuenca hidrográfica del río Gurguéia-Piauí, entre los años 1987 y 2017 con el propósito de subsidiar acciones sostenibles para la región que pertenece a la frontera actual de la región. Agronegocios brasileños. Se utilizó investigación bibliográfica y documental, así como ArcGis GIS para mapear el área. Se encontró que la cuenca presentaba variación térmica del suelo entre los años analizados, debido al aumento del suelo expuesto debido al avance de la frontera agrícola en el Estado, que en 2017 presentó en aproximadamente el $42 \%$ del área la temperatura del suelo por encima de $30^{\circ} \mathrm{C}$, pudiendo comprometer el mantenimiento de las actividades agrícolas actuales a lo largo del tiempo. De esta manera, es esencial para la sostenibilidad del medio ambiente que se lleve a cabo la planificación y gestión de la subcuenca del río Gurguéia, utilizando como parámetro la temperatura del suelo, buscando incorporar todos los recursos ambientales del área de drenaje, así como integrar el aspectos ambientales, sociales, económicos y políticos del área.

Palabras clave: Cuenca, Suelo, Temperatura, Frontera agrícola, Río Gurguéia

\section{INTRODUÇÃO}

A apropriação da natureza pelo ser humano devido à urgência da produção econômica em tornar qualquer área explorável e desconsiderando os limites físiconaturais, pode desencadear processos graves de degradação do ambiente, o que dificulta muitas vezes a sustentabilidade dos ecossistemas explorados. 
Neste contexto, a expansão do agronegócio no país tem estruturado a formação de uma nova fronteira agrícola denominada MATOPIBA, região que compreende os Estados do Maranhão, Piauí, Tocantins e Bahia, abrangendo 337 municípios em uma área de 73.173.485 hectares. No Estado do Piauí, tem-se o polo de desenvolvimento agrícola.

O Estado do Piauí apresenta um potencial agricultável, por conta de sua área de cerrados que proporcionou, a partir da década de 1990, o crescimento econômico na região Sul do Estado, devido à ocupação da fronteira agrícola, que envolve 33 municípios da bacia hidrográfica do rio Gurguéia (BANDEIRA et al., 2010).

O que se tem observado, é que as bacias hidrográficas de qualquer ordem vêm passando por fortes pressões em face das demandas dos usos dos seus recursos naturais para o desenvolvimento socioeconômico, que muitas vezes vão além da capacidade de resiliência dos seus ecossistemas (ALMEIDA e CARVALHO, 2010; ASEFA et al.,2014; GODOY e CRUZ, 2016; IORIS et al., 2008; OLIVEIRA e SILVA, 2014; TONY et al., 2015; OLIVEIRA, 2018).

Neste contexto, verifica-se a necessidade de conhecer melhor a dinâmica e as limitações de uma área, para se estabelecer diretrizes que subsidiem o manejo dos recursos naturais e adoção de restrições mais seguras quanto ao manejo do solo, por se considerar um fator físico relevante na recuperação do ambiente de bacias hidrográficas, sendo sua adequada utilização e conservação de suma importância nos processos que atuam sobre os corpos hídricos. Todavia, o ser humano o tem utilizado como um recurso inesgotável, procurando atender as suas necessidades atuais, e raramente na conservação para o uso futuro (OLIVEIRA, 2018).

A partir dessas premissas enfatiza-se a importância do uso apropriado do solo numa bacia hidrográfica, de forma a atender às características físico-naturais do ambiente, com o propósito de minimizar os impactos e possibilitar a capacidade do ambiente de se recuperar mediante as pressões exercidas.

Segundo Prado (1998), para se obter sucesso no manejo do solo é necessário conhecê-lo sob o ponto de vista químico, físico, mineralógico e morfológico, para posteriormente fazer estudos interpretativos como de potencialidade e suas limitações. 
Dessa forma, é possível promover a produtividade máxima de determinada região, como também proteger contra possíveis danos ambientais.

Destacam Diniz et al. (2013), que o conhecimento das temperaturas e propriedades térmicas do solo de uma determinada região é de fundamental importância para o entendimento dos vários processos físicos existentes nesse ambiente. Enfatizam ainda, a relevância do conhecimento da temperatura do solo, uma vez que cada tipo de solo possui características específicas, fazendo-se necessário, que sejam identificadas, para cada situação particular, as suas propriedades térmicas.

A temperatura do solo tem influência direta em vários processos ambientais como: germinação de sementes, velocidade e duração de crescimento, desenvolvimento e atividade radicular, na absorção de água e nutrientes pelas plantas e na atividade microbiana do solo, o que torna relevante o conhecimento das temperaturas e propriedades térmicas do solo para o entendimento dos vários processos físicos existentes num ambiente (SILVA et al., 2006; DINIZ et al., 2013).

A variação espaço-temporal da temperatura do solo é ocasionada por um efeito abrangente da vegetação, dos fenômenos meteorológicos (principalmente chuvas), do terreno (declividade, orientação de vertentes, altitude e diferenciação geográfica) e atividades agrícolas em diferentes escalas (SANTOS et al., 2011; CARNEIRO, 2014).

É importante o monitoramento e a modelagem da temperatura do solo, no decorrer do tempo, a fim de subsidiar ações de manejo e conservação do solo e dos principais fatores que influenciam a variação da temperatura do solo (SILVA et al., 2015)

Diante disso, nesta pesquisa foi analisada a variação da temperatura do solo, considerando os anos de 1987 e 2017, na sub-bacia hidrográfica do rio Gurguéia - BHRG, localizada em uma área de expansão do agronegócio no Piaú, uma porção do MATOPIBA no Estado, onde estão inseridos os maiores produtores de grãos do Estado, com o propósito de observar as alterações durante o período e seus efeitos para o ambiente e as atividades desenvolvidas neste recorte geográfico. 


\section{METODOLOGIA}

O método assume o caráter de um estudo descritivo e de reconhecimento, em uma perspectiva metodológica qualitativa e quantitativa, em que a ênfase é dada à situação de alteração da temperatura do solo no decorrer do tempo, a partir das classes do solo e das formas de uso e ocupação da sub-bacia hidrográfica do rio Gurguéia - BHRG.

A recolha de informação que constitui requisito fundamental para a elaboração do banco de dados que fundamentou a análise dos aspectos do solo e socioeconômico da área, organizou-se em duas etapas: a primeira com a pesquisa bibliográfica e documental em teses, livros, artigos, mapas, atlas, entre outras, que foi a principal fonte de informações secundárias, e a segunda, com o uso do geoprocessamento e levantamento de dados; nesta etapa foram usadas várias ferramentas, como imagens orbitais, mapas temáticos, hardware e o software ArcGis.

Para avaliar a variação da temperatura do solo diante das interferências ocorridas entre um período considerado, optou-se por fazer uma comparação em distintos períodos, entre os anos de 1987 e 2017 com a data para o mês de julho, por apresentar melhor qualidade e corresponder aos objetivos propostos. Tais imagens foram obtidas gratuitamente no site do Instituto Nacional de Pesquisas Espaciais - INPE. Foram utilizadas as bandas termais de cada satélite, que passaram por correções atmosféricas e de emissividade para a geração do mapa de temperatura estimada do solo utilizando do software ArcGis.

Para o mapeamento do solo da bacia foi utilizado como base as informações da EMBRAPA e do IBGE, numa escala de 1:2.000.000. Os planos de informações foram processados em sistema de coordenadas Universal Transversa de Mercator - UTM, com Datum WGS de 1984, Zona 23 Sul. A escala de representação dos mapeamentos foi na grandeza de $1: 2.800 .000$.

A obtenção de cenas dos imageadores Thematic Mapper (TM) e Operational Land Imager (OLI), respectivamente, do satélite Landsat 5 e Landsat 8, se deu junto ao banco de dados do Serviço Geológico dos Estados Unidos (USGS, 2019). As cenas em questão possuem as seguintes características (Quadro 1): 
Quadro 1 - Características das imagens Landsat utilizadas no estudo.

\begin{tabular}{|c|c|c|c|c|c|}
\hline \multicolumn{3}{|c|}{ Landsat 5 TM } & \multicolumn{3}{c|}{ Landsat 8 OLI } \\
\hline Ponto & Órbita & Data & Ponto & Órbita & Data \\
\hline 219 & $065,066,067$ & $10 / 07 / 1987$ & 220 & $065,066,067$ & $17 / 07 / 2017$ \\
\hline
\end{tabular}

Fonte: Organizado pelas autoras (2019).

Destaca-se que todas as imagens passaram por correções geométricas, enquanto as cenas do satélite Landsat 8 passaram por conversão radiométrica (16 para 8 bits). Foi empregada a ferramenta Spatial Analyst Tools e função Reclassify pertencente ao SIG ArcGIS, versão 10.2, cuja licença foi adquirida pela Universidade Federal do Piauí (UFPI).

\section{RESULTADOS}

\section{Caracterização da área de estudo}

O rio Gurguéia com extensão total de aproximadamente $532 \mathrm{~km}$, é o maior afluente do rio Parnaíba, pela sua margem direita. Sua nascente encontra-se no Município de Corrente, na cota de $500 \mathrm{~m}$ de altitude, entre as Serras de Alagoinhas e Santa Maria. No alto curso, o rio é intermitente e se torna perene a partir do médio curso quando recebe seus afluentes; dentre os principais estão os rios Paraim, Curimatá, Fundo, Corrente, Canhoto e Esfolado e os riachos da Tábua e de Santana (PIAUÍ, s/d).

$\mathrm{Na} \mathrm{BHRG}$, em sua maior parte da área, afloram sedimentos da bacia sedimentar do Parnaíba. A ocorrência de aquíferos na bacia é representada pelos sedimentos clásticos, médios a grosseiros, às vezes conglomeráticos, que constituem os aquíferos Serra Grande e Cabeças, e o Poti/Piauí. Já as formações Pimenteiras e Longá, constituídas por sedimentos clásticos finos ou pelíticos, caracterizam-se como confinantes das formações mais arenosas subjacentes (PIAUÍ, s/d).

A declividade do relevo na BHRG é predominantemente plana, em que há também áreas onduladas e forte-onduladas dispersas. As maiores inclinações estão associadas principalmente às bordas de tabuleiros e encostas de morros. As superfícies topográficas possuem altitudes entre $124 \mathrm{~m}$ a $824 \mathrm{~m}$. As áreas de maiores altitudes estão 
inseridas na porção Centro-Sul da bacia, com altimetria de 628 a 824 metros; já as de menores altitudes encontram-se na porção Norte, entre 124 a 284 m (FRANÇA et al., 2016).

A BHRG apresenta clima seco a subúmido, megatérmico e com um pequeno período chuvoso. A pluviometria média anual é de $1.000 \mathrm{~mm}$, com o trimestre mais chuvoso entre janeiro e março e o mais seco entre julho e setembro (PIAUÍ, s/d).

Conforme a Empresa Brasileira de Pesquisa agropecuária - EMBRAPA (2010), verifica-se na bacia do rio Gurguéia, o predomínio de solos do tipo Neossolo Quartzarenicos Órticos (41\%) distribuídos por toda a bacia, assim como o Argissolo Vermelho-Amarelo Distrófico (27\%) na porção Centro-Sul e Plintossolo Pétricos Concrecionários (15\%) na porção Norte, assim como Chernossolos Argilúvicos Órticos e Gleissolos Distróficos na parte Sudoeste da bacia (Figura 1).

Os Latossolos são predominantes na área e são caracterizados por apresentarem profundidade acentuada, textura variável, estrutura porosa e friável com argilas de baixa troca catiônica e minerais pouco resistentes ao intemperismo.

Os Neossolos são solos pouco evoluídos, seja pela reduzida atuação dos processos de formação ou por características inerentes ao material originário. Já os Plintossolos encontram-se em relevo plano e suave ondulado, em áreas deprimidas, planícies aluvionais e terços inferiores de encosta, situações que implicam no escoamento lento da água do solo (EMBRAPA, 2010).

A tipologia dos solos predominantes na área, quando combinadas com a declividade dos terrenos, além de favorecerem a susceptibilidade aos processos erosivos laminares, também pode provocar o assoreamento do rio e outros cursos d'água na bacia. 
Figura 1: Mapa pedológico da sub-bacia hidrográfica do rio Gurguéia.

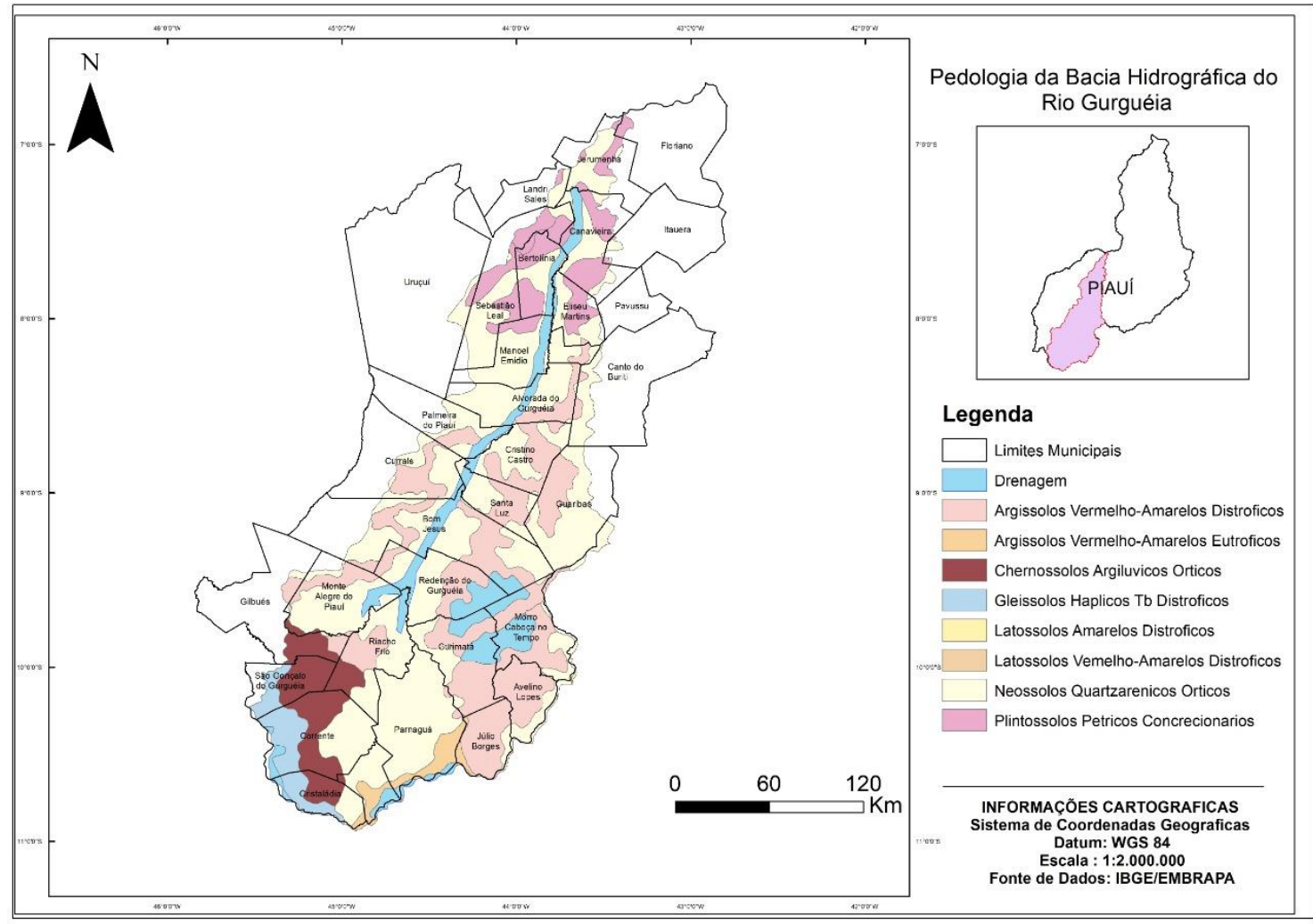

Fonte: Autores, 2019.

A BHRG apresenta predomínio de vegetação do tipo cerrado. Também estão presentes extensas áreas de caatinga, especialmente na região do Alto Gurguéia, e há também pequenas áreas de contato caatinga/cerrado (PIAUÍ, s/d).

Quanto ao aspecto econômico da BHRG, além da pecuária bovina, em especial de corte, destaca-se na bacia a produção de grãos, especialmente soja e arroz, ambos de sequeiro, decorrente principalmente da ocupação das áreas de chapadas por grandes proprietários, em sua maioria, oriundos das regiões Centro-Oeste e Sul do país.

Desta forma, o polo de desenvolvimento do Gurguéia, que engloba a microrregião do Alto-Médio Gurguéia, vivencia o crescimento econômico por meio da exploração dos cerrados para atender à demanda de exportação, sem planejamento 
socioambiental adequado para manter a sustentabilidade ambiental (BANDEIRA et al., 2010).

\section{Temperatura do solo na sub-bacia hidrográfica do rio Gurguéia}

A temperatura do solo é uma propriedade de natureza física que tem influência sobre vários processos ambientais relacionados às plantas, tais como: germinação de sementes, velocidade e duração de crescimento, desenvolvimento e atividade radicular, na absorção de água e nutrientes pelas plantas e na atividade microbiana do solo. Assim, torna-se importante o conhecimento das temperaturas e propriedades térmicas do solo para o entendimento dos vários processos físicos existentes num ambiente (GASPARIM et al., 2005; SILVA et al., 2006; DINIZ et al., 2013).

Lin et al. (2011); Santos et al. (2011) e Carneiro (2014) afirmam que a variação espaço-temporal da temperatura do solo é ocasionada por um efeito abrangente da vegetação, dos fenômenos meteorológicos (principalmente chuvas), do terreno (declividade, orientação de vertentes, altitude e diferenciação geográfica) e atividades agrícolas em diferentes escalas.

Corroboram nessa perspectiva Silva et al. (2015), ao afirmarem que o monitoramento e a modelagem da temperatura do solo ao longo do tempo é indispensável para subsidiar ações de manejo e conservação do solo e da água, e que a composição, a densidade, a umidade e a cobertura do solo, são os principais fatores que influenciam a variação da temperatura do solo.

Apontam Muller et al. (2016) que as escalas espaço-temporais desempenham importante papel na análise da resiliência do ambiente, tanto pelo fato dos processos nos ecossistemas estarem operando em uma hierarquia, como também, devido aos distúrbios caracterizados por aspectos espaço-temporais. Relatam também, que tais processos, em longo prazo, podem produzir prejuízos cumulativos e degradações, o que aumentaria a vulnerabilidade do ecossistema. Já em eventos de curta duração e com alta intensidade, o sistema tem maior probabilidade de dinâmica não-resiliente, ou seja, sem a capacidade de recuperação dos seus aspectos originais. 
Diante disso, para melhor corresponder aos objetivos propostos fez-se uma comparação espaço-temporal dos anos de 1987 e 2017 da temperatura do solo da BHRG (Figura 2), por considerar um elemento relevante para a sustentabilidade da área de pesquisa.

Figura 2: Estimativa da temperatura do solo na sub-bacia hidrográfica do rio Gurguéia em 1987 e 2017.

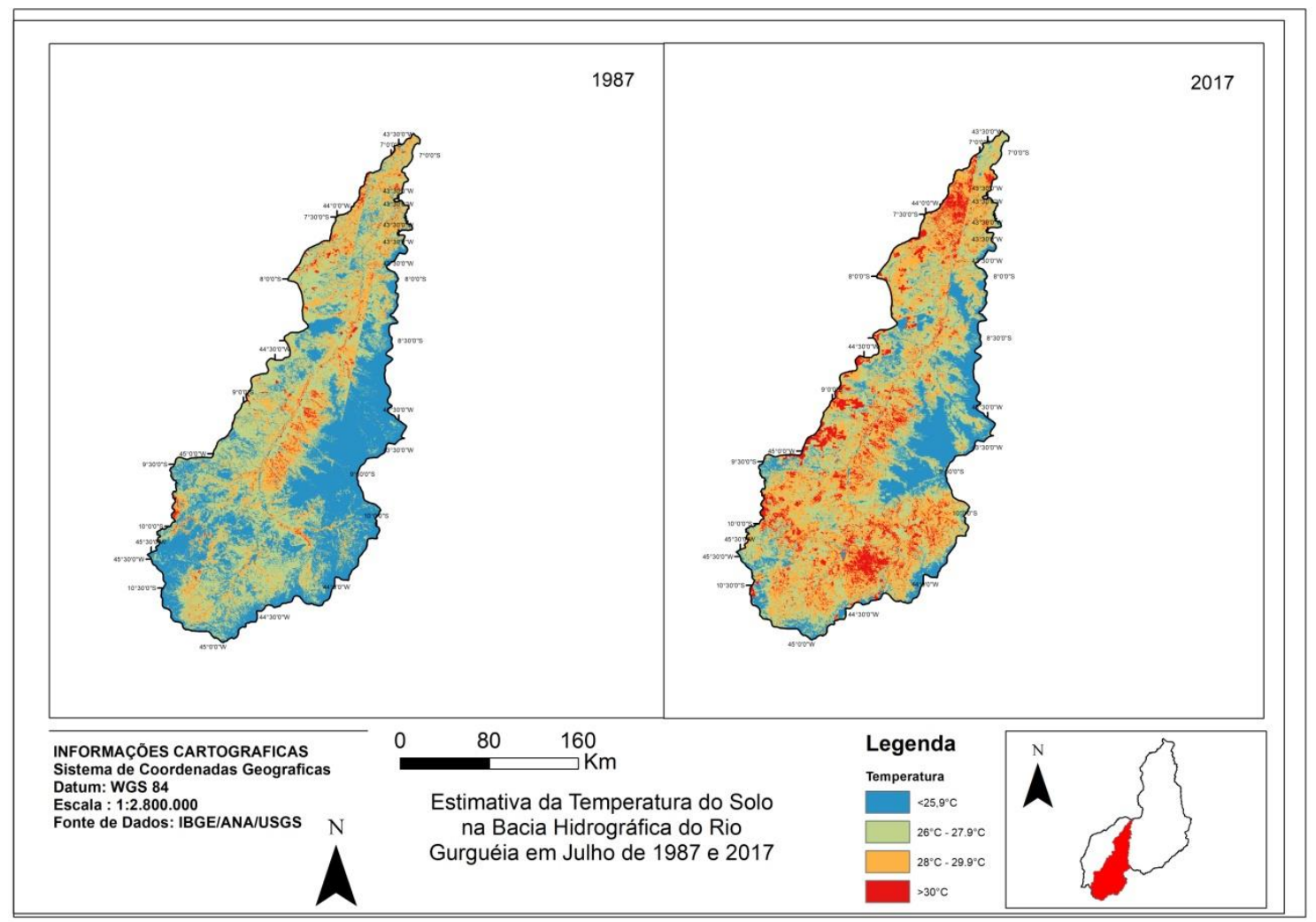

Fonte: Autores, 2019.

Observa-se na Figura 2 que houve um aumento da temperatura do solo em quase toda a área da BHRG entre os anos de 1987 e 2017, devido principalmente uma maior utilização do solo para produção agrícola.

A temperatura do solo apresentou um aumento da média de 25-26 graus para 28 a 30 graus no período analisado, principalmente nas áreas associadas aos solos do tipo Neossolos e Argissolos identificados na Figura 1, na porção do alto-médio curso da bacia onde é mais expressivo o avanço do agronegócio. Estes tipos de solos possuem como características menor capacidade de retenção de água (EMBRAPA, 2002). 
Segundo Gasparim et al. (2005) as temperaturas do solo aumentam conforme o grau de desnudamento. Discorrem ainda, que as capacidades de um solo armazenar e transferir calor são determinadas por suas propriedades térmicas e pelas condições meteorológicas do local, que, por sua vez, influenciam todos os processos químicos, físicos e biológicos do solo. A atividade microbiológica poderá ser interrompida, as sementes poderão não germinar e as plantas não se desenvolverem caso o solo não se apresente dentro de uma faixa de temperatura adequada para a manutenção dos processos fisiológicos envolvidos.

Destaca-se que as propriedades físicas da água, do ar e do solo, bem como seus movimentos e disponibilidade no solo, além de muitas reações químicas que liberam nutrientes para as plantas, são influenciados pela temperatura do solo. Além disso, o calor armazenado próximo da superfície do solo tem grande efeito na evaporação.

Quanto à fertilidade do solo, além da sua temperatura e do controle da erosão, são necessárias outras práticas que reponham os elementos nutritivos, controlem a combustão de matéria orgânica, diminuam a lixiviação, controlando, em parte, as causas de depauperamento do solo (ANSELMO, 2011).

Gasparim et al. (2005), observam que a temperatura do solo é de maior significação ecológica para a vida vegetal do que a temperatura do ar. Consideram a temperatura ideal do solo em torno de $17^{\circ} \mathrm{C}$, pois os tubérculos não crescem em temperaturas de solos superiores a $29^{\circ} \mathrm{C}$. Uma temperatura do solo desfavorável durante a estação de crescimento pode retardar ou mesmo arruinar as colheitas.

A BHRG apresenta alguns dos municípios maiores produtores de soja do Estado. Conforme a EMBRAPA (2002) a semeadura da soja não deve ser realizada quando a temperatura do solo estiver abaixo de $20^{\circ} \mathrm{C}$, porque isso prejudica a germinação e a emergência. A faixa de temperatura do solo adequada para semeadura desse grão varia de $20^{\circ} \mathrm{C} \mathrm{a} 30^{\circ} \mathrm{C}$, sendo $25^{\circ} \mathrm{C}$ a temperatura ideal para uma emergência rápida e uniforme. Desta forma, conforme observado na Figura 2 para o ano de 2017 42\% da área da bacia apresentou temperatura do solo acima de $30^{\circ} \mathrm{C}$, o que pode estar associado à substituição da vegetação original pela monocultura, podendo comprometer com o passar do tempo a 
manutenção do cultivo (Figura 3), caso não seja feito um plano de manejo adequado do solo para sua recuperação e sustentabilidade.

Figura 3: Plantação de soja no topo da Serra do Quilombo em Bom Jesus do Gurguéia Piauí em julho de 2019

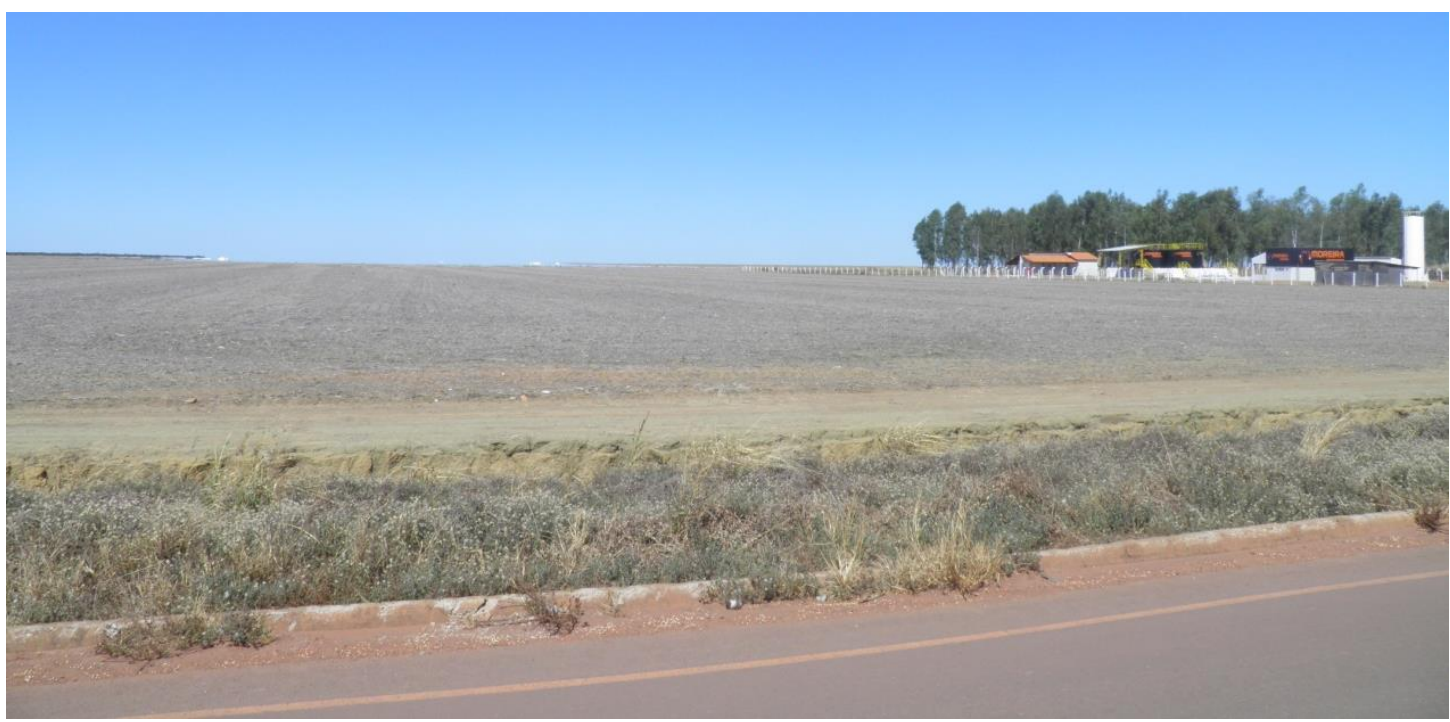

Fonte: Autores, 2019

Destaca-se que a maneira sustentável de manejo do solo com o propósito de manter sua sustentabilidade, deve ocorrer de forma que a demanda de insumos não exceda a capacidade natural de regeneração do solo. Por isso, torna-se um dos grandes desafios da atualidade aumentar a produção da terra sem provocar sua exaustão. Para tanto, é necessário o controle do uso e ocupação do solo, por meio da restrição e da fiscalização das atividades antrópicas, como forma de proteger os mananciais, sobretudo identificando as áreas mais vulneráveis à contaminação, de forma a promover um controle do uso do solo, mantendo sua sustentabilidade frente aos usos existentes.

Dessa forma, ao explorar o solo, o ser humano retira a vegetação, rompe com o arado a superfície do terreno para semear as espécies vegetais úteis às suas necessidades; então o processo erosivo adquire velocidade e intensidade, tal como ocorre no município de Gilbués, na BHRG (Figura 4), em que o manejo inadequado do solo para mineração e cultivo agrícola ao longo do tempo deixou o solo exposto e propício às erosões. Neste contexto, enquanto a natureza transforma a rocha em solo de forma lenta, o desgaste do solo pelo mau uso acontece de forma acelerada. 


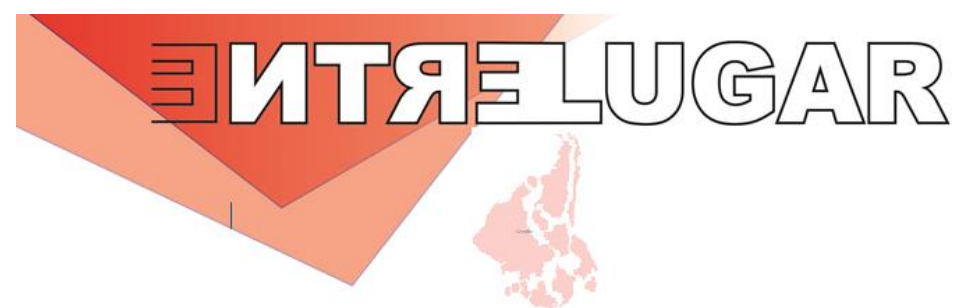

Figura 4: Processos erosivos no município de Gibués-Piauí em julho de 2019.

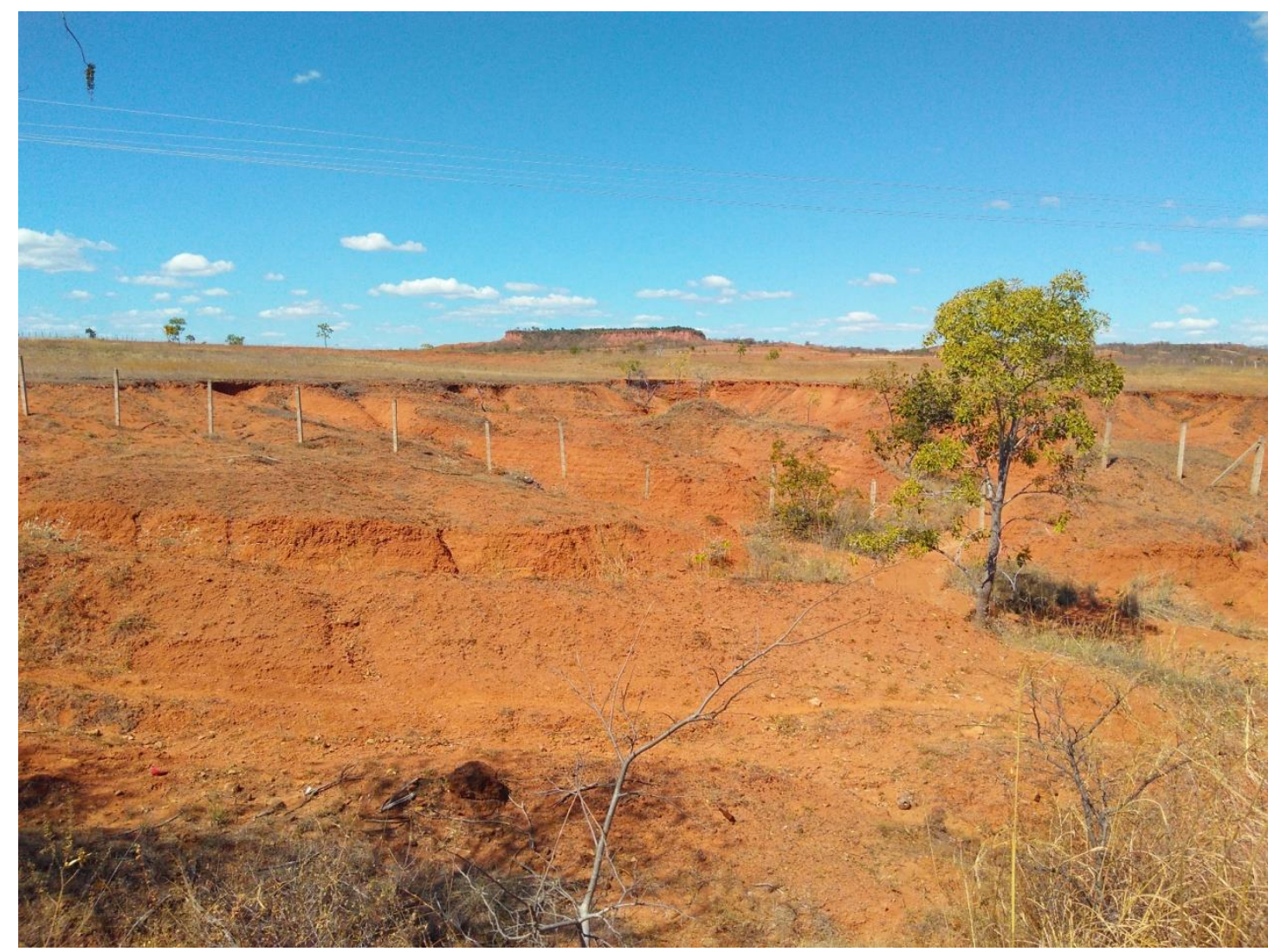

Fonte: Autores, 2019.

Verifica-se que a BHRG tem apresentado diversos problemas ambientais em função das formas de uso e ocupação desordenada da terra ao longo do tempo, com destaque para o desmatamento da vegetação primária, assim como para a erosão do solo e assoreamento dos corpos hídricos em função, principalmente, da expansão do agronegócio na bacia hidrográfica.

Oliveira e Aquino (2020), ao analisarem o uso e cobertura do solo na BHRG, constataram que a vegetação nesta bacia sofreu redução de $31,76 \%$, principalmente nas margens do rio e na porção do alto-médio curso do rio Gurguéia. Apontaram ainda que, as principais culturas desenvolvidas na área são de feijão, milho e soja, cuja produção está localizada principalmente no topo dos planaltos e chapadas.

Segundo o levantamento sistemático da produção agrícola do Instituto Brasileiro de Geografia e Estatística (IBGE, 2019), as principais culturas temporárias 
desenvolvidas na microrregião do Alto-Médio Gurguéia em 1987 eram: arroz, feijão, milho, mandioca e cana-de-açúcar. Já no ano de 2017, as principais culturas desenvolvidas nesta mesma área eram: feijão, milho e soja.

Destaca-se que ações importantes têm sido tomadas, como a criação do Comitê da Bacia Hidrográfica do Rio Gurguéia em 22 de março de 2014, com o propósito de formar uma gestão participativa com os atores sociais envolvidos, a fim de buscar maior sustentabilidade para a bacia; entretanto há necessidade de ações a curto e médio prazo a fim de manter as características originais do ambiente desta bacia.

\section{CONSIDERAÇÕES FINAIS}

A bacia hidrográfica tem sido cada vez mais utilizada como unidade de gestão na área de planejamento ambiental, numa perspectiva da conservação dos recursos naturais. Desta forma, verifica-se a relevância do conhecimento das temperaturas e propriedades térmicas do solo para o entendimento dos vários processos físicos existentes em um ambiente, assim como sua variação espaço-temporal para subsidiar ações de manejo e conservação do solo e da água para o desenvolvimento das atividades agrícolas em diferentes escalas.

Neste contexto, constatou-se que a BHRG apresentou variação térmica do solo entre 1987 e 2017, em decorrência principalmente do avanço da fronteira agrícola de grãos no Estado do Piauí. Em 2017 a bacia apresentou em aproximadamente 42\% da área temperatura do solo acima de $30^{\circ} \mathrm{C}$, podendo comprometer a manutenção das atividades agrícolas atuais no decorrer do tempo.

Dessa forma, o planejamento e o gerenciamento de bacias hidrográficas devem incorporar todos os recursos ambientais da área de drenagem, adotar uma abordagem de integração dos aspectos ambientais e socioeconômicos, bem como incluir os objetivos de qualidade ambiental para utilização dos recursos naturais. 


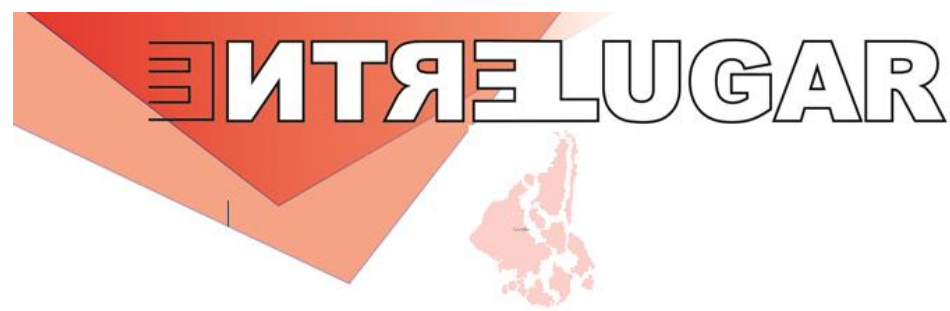

\section{REFERENCIAS BIBLIOGRÁFICAS}

ALMEIDA, L.Q. de; CARVALHO, P.F.de. Representações, riscos e potencialidades de rios urbanos: análise de um (des) caso histórico. Caminhos de Geografia Uberlândia. v. 11, $\mathrm{n}^{\mathrm{o}} .34$, p. $145-161$. jul, 2010.

ASEFA, T.; CLAYTON,J; ADAMS,A.; ANDERSON,D. Performance evaluation of a water resources system under varying climatic conditions: Reliability, Resilience, Vulnerability and beyond . Journal of Hydrology . N. 508. Pag. 53-65. 2014

ANSELMO, M. da. G. V. Caracterização e classificação de Argissolos na Reserva Legal Riacho Pacaré, Rio Tinto - PB. Trabalho de Conclusão de Curso (Graduação em Geografia) Universidade Estadual da Paraíba, Guarabira, 2011. 57f.

BANDEIRA, E. G.; ALVES, C. M. D.; MELO, L. F. de S.. Análise temporal por imagens landsat da expansão da fronteira agrícola no município Bom Jesus-PI. III Simpósio Brasileiro de Ciências Geodésicas e Tecnologias da Geoinformação. Recife - p. 001006. PE, 2010.

CARNEIRO, R.G.; MOURA, V.P.R.S.; SILVA, V. de P. R. da; SILVA JUNIOR, R. S.; ANDRADE, A. M. D. de; SANTOS, A. B. dos. Variabilidade da temperatura do solo em função da liteira em fragmento remanescente da Mata Atlântica. Revista Brasileira Engenharia Agrícola e Ambiental, Campina Grande, v.1, p. 99-108, 2014

CORTEZ, J.W; NAGAHAMA,H.de J.; OLSZEVSKI,N.; PATROCINIO FILHO, A.P.; ,E.B de SOUZA. umidade e temperatura de argissolo amarelo em sistemas de preparo e estádios de desenvolvimento do milho. Journal of the Brazilian Association of Agricultural Engineering. v.35, n.4, p.699-710, jul./ago. 2015

DINIZ, J. M. T.; SOUZA, E.P de; ARANHA, T.; MARACAJA, P.B. Avaliação da difusividade térmica do solo de Campina Grande-PB-Brasil. Agropecuária Científica no Semiárido. v. 9, p. 55-60, 2013

EMBRAPA-EMPRESA BRASILEIRA DE PESQUISA AGROPECUÁRIA. Centro Nacional de Pesquisa de Soja-CNPSO. Exigências Climáticas para a Cultura da Soja. Disponível em:〈www.cnpso.embrapa.br/retec2001/br/eclimaticas> Acesso em: 18 de junho de 2002

GASPARIM, E.; RICIERI,R. P.; SILVA, S de L.; DALLACORT, R; GNOATTO, E. Temperatura no perfil do solo utilizando duas densidades de cobertura e solo nu. Acta Scientiarum. Agronomy. v. 27, no. 1, p. 107-115, Jan./March, 2005. pp. 107-114

GODOY, V.N de, CRUZ, R.C. self-management of water resources - case study of river basin Santa Maria- RS. Ciência e Natura, Santa Maria v.38 n.2, , Mai.- Ago. p. 980 -997, 2016

IORIS, A.A.R.; HUNTER, C.; WALKER, S. The development and application of water management sustainability indicators in Brazil and Scotland. Journal of Environmental Management, vl. 88, p. 1190-1201, 2008. 


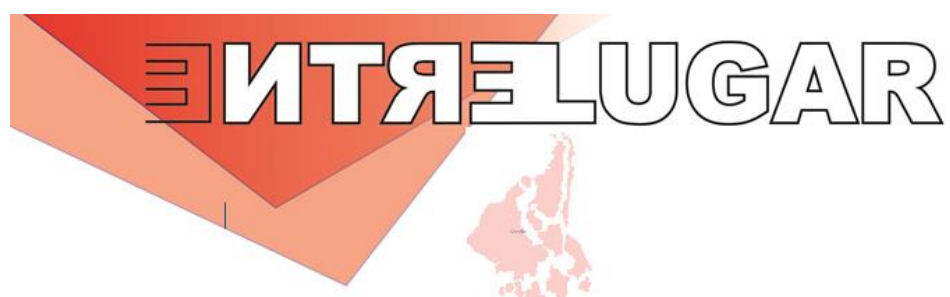

LIN, B.B. Resilience in Agriculture through Crop Diversification: Adaptive Management for Environmental Change. BioScience, V. 61, Edição 3, p. 183-193, 2011

MÜLLER, F.; BERGMANN,M.;DANNOWSKI, R..; DIPPNER, J.W .;GNAUCK, A.; HAASE, P.;JOCHIMSEN, M.C.;KASPRZAK,P.; KRÖNCKE,I.; KÜMMERLIN,R.; KÜSTER,M.; LISCHEID,G.; MEESENBURG,H.; MERZ,C.; MILLAT,G.; MÜLLER,J.; PADISÁK,J.; SCHIMMING,C.G.;THEUERKAUF， M.Assessing resilience in long-term ecological data sets. Ecological Indicators. V. 65, Jun. 2016, P $10-43$.

Disponivel

em:

<http://www.sciencedirect.com/science/article/pii/S1470160X15006305>. Acesso em: jul. 2016

OLIVEIRA, L.N; SILVA, C.E. qualidade da água do rio Poti e suas implicações para atividade de lazer em Teresina-PI. Revista Equador (UFPI), V.3, nº1, p. 128 - 147. jan./jun.,2014.

OLIVEIRA, L.N.de. Análise da capacidade de resiliência do ambiente na área do baixo curso da bacia hidrográfica do Rio Poti (Piauí). Tese de doutorado em Geografia (UFPE), 2018.131f.

OLIVEIRA, L.N.; AQUINO, C.M.S. de. DINÂMICA TEMPORAL DO USO E COBERTURA DA TERRA NA FRONTEIRA AGRÍCOLA DO MATOPIBA: análise na sub-bacia hidrográfica do rio Gurguéia-Piauí. Equador. v.9. n.1, 2020

PIAUÍ. Bacia do rio Gurguéia. Disponível em: <http://www.ccom.pi.gov.br/download/GURG.pdf. acesso em: 02 de junho de 2019.

PRADO, H. Manual de classificação de solos do Brasil. Jaboticabal, FUNEP, 1993. 218p.

SANTOS, T.E.M.; MONTENEGRO, A.A.A.; SILVA, D.D. Umidade do solo no semiárido pernambucano usando-se reflectometria no domínio do tempo (TDR). Revista Brasileira de Agrícola e Ambiental, Campina Grande, v. 7, p. 670-679, 2011.

SILVA, V.R. da; REICHERT,J.M.; REINERT,D.J. Variação na temperatura do solo em três Sistemas de manejo na cultura do feijão. Rev. Bras. Ciência do Solo, v.30, p.391399, 2006

SILVA, J.R.L da.;MONTENEGRO, A.A. de A.; MONTEIRO,A.L.N.; SILVA JÚNIOR, V. de $\mathrm{P}$ e. Modelagem da dinâmica de umidade do solo em diferentes condições de cobertura no semiárido pernambucano. Rev. Bras. Ciência Agrária. v.10, n.2, p.293303,2015

SILVA, L. D. J. Estágio de desenvolvimento e exigências da cultura da soja. UNIVAG. 2002. Disponível em: 〈http://www.univag.com.br〉. Acesso em: junio de 2019

TONY, A. C. A.; GREEN, O. O.; DECARO, D.; CHASE, A.; EWA, Jennifer-Grace. The Social-Ecological Resilience of an Eastern Urban-Suburban Watershed: The Anacostia River Basin. $67 \quad$ p., 2015. Disponível em: $<$ https://papers.ssrn.com/sol3/papers.cfm?abstract_id=2584968>. Acesso em: março de 2017. 


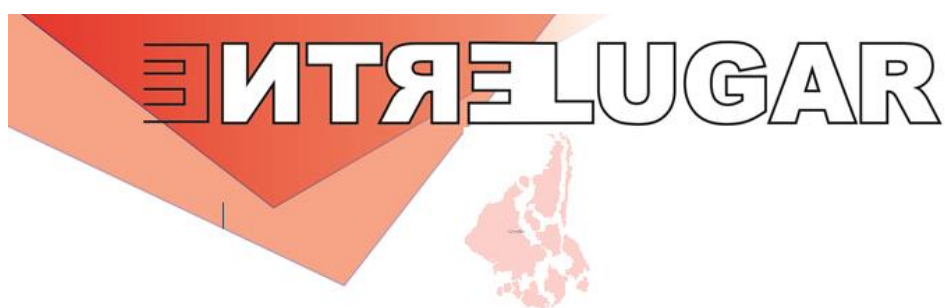

UNITED STATES GEOLOGICAL SERVICE (Serviço Geológico dos Estados Unidos).Collection: landsat archive. Disponível em: 〈http://earthexplorer.usgs.gov/>. Acesso em: 23 jul. 2019 b.

\section{AGRADECIMENTOS}

Os autores agradecem ao Programa Nacional de Pós-Graduação (PNPD/CAPES) pelo financiamento da pesquisa e ao Programa de Pós-graduação em Geografia da Universidade Federal do Piauí pelo estágio de Pós-doutorado.

Recebido para publicação outubro de 2019. Aceito para publicação em fevereiro de 2020. 